\title{
Ley General para el Control del Tabaco en México*
}

\author{
Éctor Jaime Ramírez-Barba, MD, PhD, FACS, (') Ernesto Saro-Boardman, ${ }^{(2)}$ \\ Arturo Vázquez-Guerrero, MD, ${ }^{(3)}$ Miguel Ángel Vázquez-Guerrero, MD. ${ }^{(4)}$
}

L a evidencia disponible tanto en la información gubernamental como en la literatura médica, nos lleva a la conclusión de que el impacto social de las políticas de salud realizadas hasta la fecha en materia de tabaco está aún lejos de lo deseable. La carga de la enfermedad provocada por el tabaquismo continúa siendo inmensa y la tendencia no parece disminuir. ${ }^{1-34}$ Los compromisos adquiridos por México en el ámbito internacional se han ido cumpliendo de manera parcial según lo reportó el Ejecutivo Federal. ${ }^{35,36}$ El propósito de este ensayo, es presentar el estudio de caso que dio lugar a la propuesta de Ley General para el Control del Tabaco. ${ }^{37}$ En México, el periodo de formulación del Proyecto de Ley General para el Control del Tabaco y la derogación de diversos artículos de la Ley General de Salud inició el 5 de octubre de 2006 y concluyó el 31 de agosto con su presentación en la H. Comisión Permanente durante el Primer Año de Ejercicio, segundo receso de la LX Legislatura del Honorable Congreso de la Unión. ${ }^{37}$

Para presentar antecedentes relevantes en materia de acciones reglamentarias y legislativas, para la regulación y control del tabaquismo en México, se consultaron las fuentes oficiales del Gobierno Mexicano, la literatura científica indizada y documentos de instituciones y universidades relativos a la materia del tabaco y su impacto en la salud. Asimismo, se documentó, la realización de múltiples sesiones y foros de trabajo y consulta interactiva con expertos en diferentes áreas de políticas públicas en salud sobre el control del tabaquismo y miembros de la sociedad civil.

Se creó un banco de datos electrónico, con el análisis documental de 1900 a la fecha y la mejor evidencia disponible, el cual se puso a disposición de la sociedad y los legisladores para su toma de decisiones (figura 1). Con aproximaciones repetidas trabajadas en consenso con los diversos grupos de interés, se elaboró con el máximo consenso posible la propuesta de la Ley General para el Control del Tabaco que concluyó con el proceso de elaboración del Dictamen.

Antecedentes de la legislación mexicana en materia de tabaco:

A) 1 de marzo de 1955. La primera referencia en la Legislación fue publicada en el Diario Oficial, al actualizarse el Código Sanitario. En su Capítulo VIII, titulado "Comestibles, Bebidas, Tabacos y Similares", cita en el Artículo 162: “La recolección, elaboración, depósito, transporte y comercio de tabaco y otras sustancias que se fumen, estarán controlados, en cuanto a su aspecto sanitario por la Secretaría de Salubridad y Asistencia, y sujetos a los reglamentos respectivos" ${ }^{38}$ El presidente Adolfo

\footnotetext{
* Este trabajo se basó parcialmente en la Tesis de Doctorado en Administración Pública de la Universidad Anáhuac del primer autor, titulada Evaluación de la Ley General de Salud y del Derecho a la Protección de la Salud.

(I) Universidad de Guanajuato. Hospital Ángeles León. Presidente de la Comisión de Salud de la Cámara de Diputados. México.

(2) Presidente de la Comisión de la Salud del Senado de la República, México.

(3) Comisión de Salud de la Cámara de Diputados. México.

(4) Universidad Quetzalcoatl de Irapuato. Comisión de Salud de la Cámara de Diputados. México.
}

Fecha de aceptado: 28 de abril de 2008 Solicitud de sobretiros: Dr. Éctor Jaime Ramírez-Barba. Circuito Jardín de San Juan de Dios 180, col. Jardines del Campestre, 37| 28 León, Guanajuato, México.

Correo electrónico: ector@quijote.ugto.mx 


\begin{tabular}{|c|c|c|c|c|}
\hline ACTUALIDAD & POLÍTICAS & NOTICIAS & ACCIONES & \\
\hline $\begin{array}{l}\text { DEJAR DE FUMAR } \\
\text { GALERIA } \\
\text { DOCUMENTOS } \\
\text { BENEFICIOS Y VENTAJAS }\end{array}$ & $\begin{array}{l}\text { NOTICIAS } \\
\text { Un tratado }\end{array}$ & I para el contro & venes & mats \\
\hline $\begin{array}{l}\text { EDTORIAL } \\
\text { - Para respirar mejor } \\
\text { ASPECTOS DE LA LEY GENERAL } \\
\text { DE CONTROL DE TABACO } \\
\text { - Finalidades } \\
\text { Lo fundamental } \\
\text { - Obligaciones } \\
\text { Para hacer cumplir } \\
\text { - Prohibiciones } \\
\text { Por un benelicio comin } \\
\text { - Sanciones } \\
\text { Para evilar }\end{array}$ & $\begin{array}{l}\text { Dom, t806/20 } \\
\text { En la actual } \\
\text { mortalidad } \\
\text { millones de } \\
\text { ningún otro } \\
\text { tantas persc } \\
\text { este tratado } \\
\text { miles do } \\
\text { repeccusion } \\
\text { de tabaco. } \\
\text { - Leer mis: }\end{array}$ & $\begin{array}{l}\text { Do de tabaco es } \\
\text { mundo. Habida } \\
\text { anuales relacione } \\
\text { onsumo es tan } \\
\text { thaco. Pero graci } \\
\text { puevo y pioneco, } \\
\text { personas de } \\
\text { de tabaco y de li }\end{array}$ & $\begin{array}{l}\text { a de } \\
4,9 \\
\text { aco, } \\
\text { ta a } \\
\text { in de } \\
\text { ot a } \\
\text { loras } \\
\text { umo }\end{array}$ & \\
\hline NUESTRA GALERIA & Pioneros & & & \\
\hline
\end{tabular}

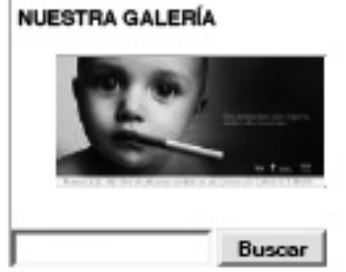

Lin, $28040008-1600$

Publicada en marzo de 2004, la ley de ambientes libres de humo de Irlanda oo considera el momento clave para la salud pública mundial. La primera ley nacional del mundo en lograr que lodos los lugares de trabejo cerradoe sean $100 \%$ libres de humo ha lenido efectos mucho mas alla de las coetas de Irlanda.

- Leer más

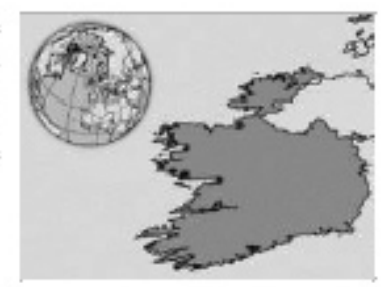

FIGURA I. WWW.MEJORSIINTABACO.ORG.MX

Ruiz Cortines (1952-1958) en su tercer informe de gobierno destacó las condiciones halagadoras de la industria de la transformación, habiendo incrementos del índice general de volumen de tabaco. ${ }^{39}$

B) 1961. El presidente Adolfo López Mateos (1958-1964) expresó en sus informes "el registro de compraventa de tabaco"; "los créditos privados para explotaciones agrícolas y forestales de los ejidos, tales como..., tabaco"; "Mejoró los precios del tabaco en 15\% para alentar los productores"; y el "tabaco fue materia de operaciones compensadas". 40

C) 13 de marzo de 1973. El último Código Sanitario se actualizó y publicó en el Diario Oficial de la Federación (DOF) bajo la presidencia de Luis Echeverría
Álvarez (1970-1976) y la XLVIII Legislatura. ${ }^{41}$ En la exposición de motivos del Ejecutivo se decía: "La Iniciativa no contiene disposiciones que prohíban la producción y venta de bebidas alcohólicas y tabaco, pero tampoco desconoce la necesidad de reglamentar estrictamente su elaboración, propaganda y suministro con el propósito de proteger la salud de la población y de lograr que el salario de los trabajadores y el ingreso de los campesinos se destine fundamentalmente a satisfacer sus necesidades personales y familiares, sobre todo en lo tocante a habitación, nutrición y educación". Se expresó también que: "Tocante al tabaco que usa el hombre principalmente para fumar, se desea llamar 
la atención de los fumadores sobre el posible perjuicio que a su salud puede ocasionar el uso y sobre todo el abuso de este producto. Por esa causa se determina que en las etiquetas y contra-etiquetas de los envases en que se expenda o suministre tabaco, debe figurar en forma clara y visible la leyenda: este producto puede ser nocivo para la salud, pues pretende un plan reformativo y educativo, prevenir a la comunidad de los trastornos a la salud en general, por el uso o el abuso de este producto, ampliando así, la finalidad fundamental de este Ordenamiento de preservar y mejorar la salud". Igualmente se señala que la propaganda relacionada con aquella sustancia se referirá básicamente a su calidad, origen y pureza y no inducirá a su consumo por razones de estímulo, de bienestar o de salud, no debiendo utilizarse en ella personajes adolescentes o niños o asociarse en alguna forma con actividades deportivas, del hogar o del trabajo.

En el debate legislativo de la iniciativa, se debatió sobre la juventud y drogadicción en México, vaticinando un futuro ominoso y que el mejor de los casos sería sólo el consumo de alcohol y de tabaco. Se estableció claramente que la Secretaría de Salubridad tenía especial interés en erradicar el uso de estos productos que pueden ser nocivos para la salud, aunque no existía la certeza documental, de la asociación causa-efecto que permitiera establecer fumadores vínculo entre tabaquismo y cáncer pulmonar, enfisemas $u$ otros padecimientos. Por otro lado, en nuestro país no estaba prohibida la producción de productos de tabaco y alcohol; así como su comercialización y difusión a través de medios de comunicación masiva.

D) 1971. El presidente Echeverría en su informe presidencial hacía referencia al desorden que prevalecía en la producción tabacalera como resultado de una injusta distribución de las utilidades entre agricultores y empresarios, resolviendo el Ejecutivo comprar la compañía extranjera que controlaba la mayor parte de la producción y distribución del tabaco, fundando Tabacos Mexicanos, estableciendo un nuevo equilibrio entre estos sectores, con el resultado de que el ingreso de los campesinos se incrementó $184 \%$ en relación con el periodo anterior. Otra política asumida, en este periodo, fue la reestructuración de la tarifa en el impuesto sobre tabacos labrados, disminuyendo las tasas a los de consumo popular y aumentando las correspondientes a los de mayor precio. Como parte de sus informes posteriores, daba cuenta que se cultivaron 40000 hectáreas con 72000 toneladas de tabaco seco con valor de 700 millones de pesos, y en el último año que los campesinos productores de tabaco obtuvieron una utilidad de 455 millones de pesos, además de la afiliación al Instituto Mexicano del Seguro Social. ${ }^{42}$

En el Código Sanitario (octavo) publicado, aparece por primera ocasión en la Ley el Control Sanitario del Tabaco como materia de Salubridad General en el Artículo 3ㅜㅜ Fracción IX. En el Artículo 37 establecía en su 2 Párrafo que la publicidad o propaganda de las bebidas alcohólicas y del tabaco se ajustará a lo autorizado por la propia Secretaría en los términos del Código Sanitario y sus reglamentos.

Además se incorporó un Título Undécimo “Del Control de Alimentos, Bebidas no Alcohólicas, Bebidas Alcohólicas, Tabaco, Medicamentos, Aparatos y Equipos Médicos, Productos de Perfumería, Belleza y Aseo, Estupefacientes, Substancias Psicotrópicas, Plaguicidas y Fertilizantes". En el Art. 212 se estableció la competencia de la Secretaría de Salubridad y Asistencia en el control sanitario del tabaco. Se adicionó el Capítulo IV titulado "Del Tabaco" con los siguientes artículos:

Art. 249. Para los efectos del presente Código, con el nombre de tabaco se designan todos los productos fabricados a partir de la planta Nicotina Tabacum que utiliza el hombre para fumar, mascar o absorber.

Art. 250. En las etiquetas y contraetiquetas de los envases en que se expenda o suministre tabaco, además de lo establecido en el Art. 233 debe figurar en forma clara y visible la leyenda: "Este producto puede ser nocivo para la salud".

Art. 251. La propaganda del tabaco se referirá a su calidad, origen, pureza y no inducirá a su consumo por razones de estímulo, de bienestar o salud, no debiendo fumarse frente al público, real o aparentemente, ni utilizarse en ella personajes adolescentes o niños o asociarse a alguna forma con actividades deportivas, del hogar o del trabajo.

Art. 252 Para el control sanitario del tabaco en materia de adulteración, contaminación y alteración, se aplicarán los Artículos 235, 236 y 237 de este Código.

Art. 444. Señalaba que la infracción al Art. 250 se sancionará con multa de un mil a cincuenta mil pesos. El Art. 445 que la Infracción al Art. 251 se sancionará con multa de cien a quince mil pesos. El Art. 504. Establecía la sanción de prisión de tres meses a dos años y multa de un mil a veinticinco mil pesos por faltas a los Artículos 250 y 251. El Art. 506 establecía la sanción de prisión de uno a seis años y multa de un mil a diez mil pesos por faltas al Artículo 252. El Art. 508 decía que al que 
comercie, distribuya o venda tabaco adulterado o contaminado, con conocimiento de esta circunstancia, se le impondrá prisión de seis meses a tres años y multa de un mil a diez mil pesos.

E) 1978. El presidente José López Portillo (1976-1982) informaba: "que las exportaciones de bienes mejoraron y no sólo suma el petróleo, sino también otros productos de alta redituabilidad como: algodón, tabaco, hortalizas, café, fresas, cacao y plátanos, que a pesar de las bajas especulativas y trucos de los erráticos mercados internacionales, dieron a la balanza comercial agropecuaria un saldo favorable, al cerrar 1977, de 17 mil millones de pesos". 43

F) 24 de febrero de 1984. En el gobierno del presidente Miguel de la Madrid Hurtado (1982-1988) se incorpora a la Constitución Política el Derecho a la Protección de la Salud en el Art. 4º . La Ley reglamentaria fue denominada Ley General de Salud (LGS) y publicada en el $\mathrm{DOF}^{44}$ En la exposición de motivos de la LGS presentada por el Ejecutivo se señalaba que el tabaco en la planta nicotina tabacum y sus sucedáneos, en su forma natural o modificada y en las diferentes presentaciones que se utilicen para fumar, masticar o aspirar y, como un apoyo al programa contra el tabaquismo, ordena que en el empaque o envase aparezca, en forma clara y visible, la leyenda relativa a que dicho producto pueda ser nocivo para la salud, escrito con letra fácilmente legible y en colores contrastantes y que en ningún caso y de ninguna forma se podrá expender tabaco a menores de edad.

En la LGS se incorporó en el Título XII Programas Contra las Adicciones, Capítulo II, el Programa Contra el Tabaquismo con el siguiente articulado:

Art. 188. La Secretaría de Salubridad y Asistencia, los gobiernos de las entidades federativas y el Consejo de Salubridad General, en el ámbito de sus respectivas consecuencias, adoptarán las medidas contra el tabaquismo, que comprenderán entre otras, las siguientes acciones:

I. La prevención y el tratamiento de padecimientos originados por el tabaquismo, $y$

II. La educación sobre los efectos del tabaquismo en la salud, dirigido especialmente a la familia, niños y adolescentes, a través de métodos individuales, colectivos o de comunicación masiva.

Art. 189. Para poner en práctica las acciones contra el tabaquismo, se tendrán en cuenta los siguientes aspectos:

I. La investigación de las causas del tabaquismo y de las acciones para controlarlas, y

II. La educación a la familia para prevenir el consumo del tabaco por parte de niños y adolescentes.

Art. 190. En el marco del Sistema Nacional de Salud, la Secretaría de Salubridad y Asistencia coordinará las acciones que se desarrollen contra el tabaquismo, promoverá y organizará servicios de orientación y atención a fumadores que deseen abandonar el hábito y desarrollará acciones permanentes para disuadir y evitar el consumo de tabaco por parte de niños y adolescentes.

La coordinación en la adopción de medidas en los ámbitos federal y local se llevará a cabo a través de los acuerdos de coordinación que celebre la Secretaría de Salubridad y Asistencia con los gobiernos de las entidades federativas.

El Título XIII se tituló del “Control sanitario de tabaco entre otros elementos". El Art. 194 señala que compete a la Secretaría de Salubridad y Asistencia en su Fracción I: "El control sanitario del proceso, importación y exportación de tabaco, sustancias tóxicas que constituyan un riesgo para la salud, así como de las materias primas que intervengan en su elaboración".

Al Capítulo XI se le tituló "Tabaco". El ordenamiento señalaba en el Art. 275. "Para los efectos de esta Ley, con el nombre de tabaco se designa a la planta 'Nicotina tabacum' y sus sucedáneos, en su forma natural o modificada, en las diferentes presentaciones, que se utilicen para fumar, masticar o aspirar".

El Art. 276. En las etiquetas de los empaques y envases en que se expenda o suministre tabaco, además de lo establecido en el Art. 210 de esta Ley, en lo conducente, deberá figurar en forma clara y visible la leyenda "Este producto puede ser nocivo para la salud", escrito con letra fácilmente legible, en colores contrastantes y sin que se invoque o se haga referencia a alguna disposición legal. El Art. 277. En ningún caso y de ninguna forma se podrá expender tabaco a menores de edad.

Del Título XIV: "Publicidad". El Art. 308. La publicidad de bebidas alcohólicas y del tabaco deberá ajustarse a los siguientes requisitos:

I. Se limitará a dar información sobre las carac- 
terísticas calidad y técnicas de elaboración de estos productos;

II. No deberá presentarlos como productores de bienestar o salud, o asociarlos a celebraciones cívicas o religiosas;

III. No podrá asociar a estos productos con ideas o imágenes de mayor éxito en la vida afectiva y sexualidad de las personas o hacer exaltación de prestigio social, virilidad o feminidad o atentar contra la dignidad de la mujer;

IV. No podrá asociar estos productos con actividades creativas, deportivas, del hogar o del trabajo, ni emplear imperativos que induzcan directamente a su consumo;

V. No podrá incluir, en imágenes o sonidos, la participación de niños adolescentes ni dirigirse a ellos, y

VI. En el mensaje, no podrán ingerirse o consumirse real o aparentemente los productos de que se trata.

El Art. 309. Los horarios en los que las estaciones de radio y televisión y las salas de exhibición cinematográfica podrán transmitir o proyectar, según el caso publicidad de bebidas alcohólicas o de tabaco, se ajustarán a lo que establezcan las disposiciones generales aplicables. ${ }^{44}$ Las sanciones incluían de 50 a 400 salarios mínimos (SM) si hacían una infracción al Art. 276; de 0 a 500 SM al los Art. 277 y 309; de 10 a 100 SM al Artículo 308.

Del proceso legislativo en Comisión Dictaminadora se menciona como clave que el control sanitario de la publicidad de las bebidas alcohólicas y del tabaco, revisten especial importancia dado el abuso que actualmente se hace de dicha publicidad.

El Derecho a la Protección de la Salud y la nueva Ley General de Salud crearon gran expectativa. El presidente De la Madrid informaba que las adecuaciones introducidas en impuestos recaían solamente en los estratos de ingresos medios y superiores, así como en el consumo de artículos no indispensables tales como el tabaco y las bebidas alcohólicas. ${ }^{45}$

G) El 27 de mayo de 1987. En la administración del presidente De la Madrid se propuso la primera reforma a la Ley General de Salud en el Diario Oficial de la Federación, ${ }^{46}$ en materia de tabaco los cambios fueron: adición de un segundo párrafo al Art. 276 que establecía: "Las disposiciones reglamentarias señalarán las demás leyendas de advertencia que deban figurar en la forma y términos señalados en el anterior párrafo, a fin de advertir a grupos determinados de población como mujeres en estado de gestación, personas con afecciones cardiacas o respiratorias y otras, de los riesgos específicos que provoca el consumo de tabaco".

Adición al Art. 308. Fracción VII. “En el mensaje no podrán participar personas menores de 25 años". VIII. "En el mensaje deberán apreciarse fácilmente, en forma visual o auditiva, según el medio publicitario que se emplee, las leyendas a que se refieren los Artículos 218 y 276 de esta ley".

La Secretaría de Salud podrá dispensar el requisito previsto en la Fracción VIII del presente Artículo, cuando en el propio mensaje y en igualdad de circunstancias, calidad, impacto y duración, se promueva la moderación en el consumo de bebidas alcohólicas, desaliente el consumo de tabaco, especialmente en la niñez, la adolescencia y la juventud, así como advierta contra los daños a la salud que ocasionan el abuso en el consumo de bebidas alcohólicas y el consumo de tabaco. Las disposiciones reglamentarias señalarán los requisitos a que se sujetará el ordenamiento de la dispensa a que se refiere el párrafo anterior.

Se reformó el del Título XIII, el Capítulo I, denominándolo: "Consejo Nacional Contra las Adicciones (CONADIC)". Se adicionó el Artículo 184-Bis. "Se crea el CONADIC, que tendrá por objeto promover y apoyar las acciones de los sectores público, social y privado tendientes a la prevención y combate de los problemas de salud pública causados por las Adicciones que regula el presente Título, así como proponer y evaluar los programas a que se refieren los Artículos 185, 188 y 191 de esta Ley. Dicho Consejo estará integrado por el Secretario de Salud, quien lo presidirá, por los titulares de las dependencias y entidades de la Administración Pública Federal cuyas atribuciones tengan relación con el objeto del Consejo y por representantes de organizaciones sociales y privadas relacionadas con la salud. El Secretario de Salud podrá invitar, cuando lo estime conveniente, a los titulares de los gobiernos de las entidades federativas a asistir a las sesiones del Consejo. La organización y funcionamiento del Consejo se regirán por las disposiciones que expida el Ejecutivo Federal".

En la exposición de motivos se expuso que si de por sí las adicciones son conductas de suyo reprobables, debe ser motivo de mayor preocupación que los hábitos nocivos no se extiendan afectando a nuestros menores y jóvenes, por lo que vemos con particularidad simpatía que se prohíba también el suministro de bebidas alcohólicas y de tabaco a menores de edad. Así como que en la publicidad de estos productos no participen quienes tengan me- 
nos de 25 años, para que no sirva de malos ejemplos, y que las leyendas de advertencia figuren no sólo en los productos sino también en la publicidad que de éstos se realice. En cuanto a la sustitución de la leyenda de advertencia en los envases y empaques de tabaco, no está en entredicho su benevolencia y también se justifica por sí sola, máxime que en numerosos países de mayor e inclusive de menor desarrollo al nuestro, ya se exige de tal leyenda sea categórica en el sentido de advertir que el tabaco es nocivo para la salud.

H) El 14 de junio de 1991. En la presidencia de Carlos Salinas de Gortari (1988-1994) se publicó la tercer reforma a la LGS, ${ }^{47}$ reformando el Art. 276: "En las etiquetas de los empaques y envases en que se expenda o suministre tabaco, además de lo establecido en las normas técnicas correspondientes, deberán figurar en forma clara y visible leyendas de advertencia escritas con letra fácilmente legible con colores contrastantes, sin que se invoque o haga referencia a alguna disposición legal; las cuales se sustituirán como mínimo cada seis meses, alternando cada uno de los contenidos siguientes:

I. Dejar de fumar, reduce importantes riesgos a la salud.

II. Fumar, es un factor de riesgo para el cáncer y el enfisema pulmonar y

III. Fumar durante el embarazo, aumenta el riesgo de parto prematuro y de bajo peso en el recién nacido."

Las disposiciones reglamentarias señalarán los requisitos a que se sujetará el uso de las leyendas a que se refiere este artículo.

Reforma al Art. 286. En materia de alimentos, bebidas no alcohólicas, productos de perfumería, belleza y aseo, tabaco, así como de las materias que se utilicen en su elaboración el secretario de Salud, mediante acuerdo publicado en el Diario Oficial de la Federación, determinará con base en los riesgos para la salud qué productos o materias primas requieren autorización previa de importación.

La motivación expresada fue la siguiente: “ $\mathrm{La}$ publicidad deberá cumplir con las características que fije la autoridad sanitaria respectiva. Para evitar publicidad distorsionada o falaz, quienes la realicen deberán contar con previa autorización de la Secretaría de Salud, en forma muy especial cuando se trate de insumos para la salud, de bebidas alcohólicas o de tabaco, así como de otros productos que determines el reglamento de la materia".
El presidente Salinas de Gortari informaba a la nación que: "Empresas como Tabacos Mexicanos se encontraban en proceso de ser reestructuradas, liquidadas o transferidas a las organizaciones de productores". ${ }^{48}$

I) 31 de mayo de 2000. En la presidencia de Ernesto Zedillo Ponce de León se registró la sexta modificación a la LGS, publicándose en el DOF la primer iniciativa de reforma por parte del Legislativo ${ }^{49}$ que modificaba la Fracción II del Art. 188, añadiéndole: "la prohibición de fumar en el interior de los edificios públicos propiedad del Gobierno Federal, en los que alberguen oficinas o dependencias de la Federación y en aquellos en los que se presten servicios públicos de carácter federal, con excepción de las áreas restringidas reservadas en ellos para los fumadores".

La motivación expresada fue la urgencia de hacer medidas preventivas, iniciando en los edificios federales.

J) 27 de julio del 2000. Utilizando su Facultad Reglamentaria el presidente Zedillo publicó en el DOF el "Reglamento sobre Consumo de Tabaco" que entró en vigor 30 días después. ${ }^{50} \mathrm{El}$ objeto del "Reglamento" (Art. 1) era proteger la salud de las personas de los efectos nocivos causados por la exposición al humo del tabaco, con la reducción del consumo de éste, principalmente, en lugares públicos cerrados. En el Capítulo II (Art. 5 a 8) señalaba que la prevención del tabaquismo tiene carácter prioritario, principalmente en la infancia y en la adolescencia; señalaba las acciones tendientes al tratamiento del tabaquismo y un artículo sobre la investigación sobre el tabaquismo. El Capítulo III (Art. 9 a 15) era explícito respecto de dónde estaba prohibido fumar, destinando un lugar donde sí podría fumar y las características del mismo; anunciando con letreros que expresaran la prohibición de hacerlo y la obligación de los funcionarios para difundir estas medidas. El Capítulo IV (Art. 16 a 18) establecía los mecanismos de coordinación entre la Federación y las entidades federativas. El Capítulo V (Art. 19) daba la responsabilidad a la Secretaría de Salud del cumplimiento del "Reglamento" y el Capítulo VI (Art. 20 y 21) señalaban las sanciones administrativas al que incumpliera.

K) 1 de enero de 2002. se publica en el $D F^{51}$ una reforma a la Ley sobre el Impuesto Especial sobre Productos y Servicios (LIEPS). Se incrementó el impuesto a los tabacos labrados de manera gradual. En los cigarros con filtro a $105 \%$ en $2002 ; 107 \%$ en 
$2003 ; 110 \%$ en 2004 y 2005. En los cigarros sin filtro $50 \%$ en $2002 ; 80 \%$ en $2003 ; 100 \%$ en 2004 y $100 \%$ en 2005. Los puros y otros tabacos labrados fueron gravados con una tasa de 20.9 por ciento.

L) 31 de diciembre de 2003. El Art. 195 establecía en cuanto a los servicios que presta la autoridad sanitaria para actividades reguladas por la misma (Fracción I): "Por el trámite y en su caso, expedición del permiso sanitario en materia de publicidad, si ésta se refiere a tabaco, se pagará el derecho a que se refiere este artículo conforma al doble de las cuotas señaladas en el mismo". ${ }^{2}$

M) 19 de enero de 2004. Se publicó la décimo cuarta modificación a la LGS y fue en materia de tabaco, fue promulgada en la administración del presidente Vicente Fox Quezada ${ }^{53}$ para quedar en los siguientes términos:

Reforma del Art. 276. “En [...] establecido en las normas oficiales mexicanas [...] con un tamaño equivalente al veinticinco por ciento por lo menos en cualquiera de las caras frontales o traseras de las cajetillas, en adición a una leyenda de advertencia en una de las caras laterales de las cajetillas, las cuales se alternarán con los contenidos siguientes:

II. Fumar es causa de cáncer y enfisema pulmonar, $y$

Las etiquetas de los empaques y envases en que se expenda o suministre tabaco contendrán una inserción perfectamente visible en una de sus caras, con mensajes para orientar al fumador hacia programas de tratamiento para dejar de fumar.

Las disposiciones reglamentarias señalarán los requisitos a que se sujetará el uso de las leyendas y mensajes a que se refiere este artículo.

La Secretaría de Salud, en su caso, publicará en el DOF el acuerdo mediante el cual podrán establecerse otras leyendas precautorias, así como las disposiciones para su aplicación y utilización."

Adición al segundo y tercer párrafo al Art. 277. “[...] No se venderán o distribuirán cigarros a los consumidores en empaques que contengan menos de catorce cigarros, cigarros sueltos o tabaco picado en bolsas de menos de diez gramos. No se venderán o distribuirán cigarrillos en farmacias, boticas, hospitales ni escuelas de nivel preescolar hasta bachillerato o preparatoria".

Adición al Art. 277 bis. "Las unidades hospitalarias y clínicas del sistema nacional de salud, deberán contar con áreas en donde se prohíba el consumo de tabaco. Se consideran como tales las de atención médica, auditorios, aulas y zonas de peligro para la seguridad laboral y colectiva, así como los sitios de trabajo de ambiente cerrado.

La Secretaría de Salud en su caso, los gobiernos de las entidades federativas reglamentarán las áreas restringidas para los fumadores."

Adición al Art. 308 bis. "La publicidad de tabaco deberá observar, además de las mencionadas en el Art. 308, los siguientes requisitos:

I. No podrá asociarse a este producto ideas o imágenes atléticas o deportivas y popularidad; ni mostrar celebridades o figuras públicas, o que éstos participen en su publicidad;

II. En el mensaje, no podrán manipularse directa o indirectamente los recipientes que contengan a los productos;

III. No podrán distribuirse, venderse u obsequiarse, directa o indirectamente, ningún artículo promocional que muestre el nombre o logotipo de productos de tabaco, salvo aquellos que sean considerados como artículos para fumadores. La distribución de muestras de productos de tabaco queda restringida a áreas de acceso exclusivo a mayores de 18 años;

IV. No podrán distribuirse, venderse u obsequiarse a menores de edad artículos promocionales o muestras de estos productos, $\mathrm{y}$

V. No deberá utilizar en su producción dibujos animados, personajes virtuales o caricaturas."

Art. 309 bis. "La exhibición o exposición de la publicidad de tabaco se sujetará a las siguientes disposiciones:

I. Queda prohibida toda publicidad de tabaco en revistas dirigidas a niños, adolescentes o aquellas con contenidos educativos, deportivos o de salud, no podrán aparecer en portada, contraportada, tercera y cuarta de forros, de revistas, periódicos o cualquier otra publicación impresa; así como su colocación en lugares, páginas o planas adyacentes a material que resulte atractivo para menores de edad;

II. Queda prohibida toda publicidad de tabaco en radio y televisión. En salas de proyección cinematográfica queda prohibida toda publicidad de tabaco en las proyecciones a las que puedan asistir menores de edad. Queda prohibida toda publicidad de tabaco en internet a menos y hasta que se disponga de la tecnología para que cada persona que busque acceso al sitio de internet en el cual dicha publicidad se 
pretenda trasmitir, provea la verificación de que el usuario o receptor es mayor de edad;

III. Ninguna publicidad exterior de tabaco podrá situarse a menos de 200 metros de cualquier escuela de educación inicial, jardines de niños, educación especial, primarias, secundarias y nivel medio superior; así como de hospitales, parques recreativos y clubes deportivos, educativos o familiares. Así mismo, no se podrá localizar publicidad en anuncios exteriores que excedan en su tamaño total 35 metros cuadrados, sea de manera individual o en combinación intencional con otra publicidad;

IV. Queda prohibida toda publicidad de tabaco en las farmacias, boticas, hospitales y centros de salud, y

V. Queda prohibido patrocinar a través de publicidad de tabaco, cualquier evento en el que participe o asistan menores de edad."

Modificación del Art. 421. "Se sancionará con una multa equivalente de cuatro mil hasta diez mil veces el salario mínimo general diario vigente en la zona económica de que se trate la violación de las disposiciones contenidas en los artículos anteriores de esta Ley".

En la exposición de motivos señalan con claridad que la publicidad es un factor que debe atenderse a fin de disminuir las enfermedades por tabaco.

N) 12 de mayo de 2004. Es publicado el Decreto donde el Senado de la República aprueba el Convenio Marco para el Control del Tabaco (CMCT) de la Organización Mundial de la Salud (OMS). ${ }^{54}$

O) 28 de mayo de 2004. El Consejo de Salubridad General publica el DOF ${ }^{55}$ el Acuerdo por el que se emite recomendación a fin de proteger la salud de los no fumadores por la exposición involuntaria al humo del tabaco. Recomienda a los gobiernos de las entidades federativas a emitir o fortalecer disposiciones de carácter general para proteger a los no fumadores. También recomiendan expedir certificados de establecimientos libres de humo e informar de los avances al Consejo Nacional contra las Adicciones.

P) 18 de junio de 2004. La Secretaría de Salud por conducto del CONADIC y la Comisión Federal para la Protección contra Riesgos Sanitarios (COFEPRIS), suscribió un convenio con las principales tabacaleras en México: British American Tobacco México y Philip Morris México. El convenio pretendía ampliar la regulación y normatividad relativas al tabaco, su publicidad, comercialización y leyendas de advertencia de los productos de tabaco. Además estableció el mecanismo, las características, la temporalidad y el destino de la aportación temporal que cubrirán al Fondo de Protección contra Gastos Catastróficos los productores y comercializadores. Madrazo-Lajous y colaboradores realizaron un análisis jurídico, publicado en la Revista de Salud Pública de México, en el cual se ilustra el grado en que incide la falta de supervisión adecuada de las acciones gubernamentales en la implementación de políticas públicas. ${ }^{14}$

Q) 30 de julio de 2004. Se publicó en el DOF el Decreto que en por el que se exime del pago de los impuestos IEPS e IVA (impuesto al valor agregado). En términos prácticos exentaba de estos impuestos por la enajenación de cigarros, puros y otros tabacos labrados correspondientes al incremento de hasta cinco centavos que se dé, por parte de las tabacaleras y sus comercializadores o distribuidores, al precio de enajenación de cada uno de esos bienes, y que tal incremento debería ser aportado al Fondo de Protección contra Gastos Catastróficos, siendo deducible en los términos de la Ley del Impuesto sobre la Renta. ${ }^{56}$

R) 25 de febrero de 2005. En la administración del Lic. Vicente Fox, se publicó en el DOF ${ }^{57}$ el Decreto promulgatorio del CMCT de la OMS para su debida observancia en el territorio nacional, conforme la facultad que le otorga la Carta Magna en el Art. 79, Fracción I. En la publicación se transcriben los 38 artículos del CMCT.

S) Marzo-abril de 2005. La Suprema Corte de Justicia de la Nación otorgó el amparo a farmacias en sus

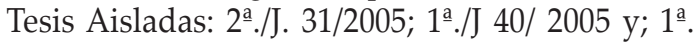
XXIX/2005 dado que la reforma hecha a la LGS en su Artículo 277 tercer párrafo del 19 de enero de 2004 es violatoria de las garantías que otorga la Constitución por lo siguiente: se advierte que dicha adición estuvo dirigida a ejercer un control más estricto sobre la publicidad del tabaco para evitar o disminuir su consumo; sin embargo, no puede tomarse en consideración para justificar la prohibición de vender o distribuir cigarros en farmacias o boticas, en virtud de que podrán adquirirse en los comercios a los que no les aplica tal limitación. Por lo tanto, al no existir una razón suficiente que demuestre la necesidad o conveniencia de prohibir la venta o distribución de cigarros sólo en aquellos establecimientos, ni justificarse el trato diferenciado que se les da respecto del resto de los comercios, cabe concluir que el tercer párrafo del referido Artículo 277 viola la garantía de igualdad 
inherente a la libertad de comercio, que tutela el Artículo 5o de la Constitución Politica de los Estados Unidos Mexicanos. ${ }^{58}$ No existe una razón válida para impedir a los establecimientos comerciales señalados que desarrollen actividades lícitas como expender productos que se encuentran legalmente dentro del comercio, máxime cuando al respecto no existe una justificación que sustente el interés de la sociedad y que tienda a proteger sus derechos, en tanto que si el objetivo de la citada disposición legal es inhibir la venta de tabaco, no se justifica que la mencionada prohibición únicamente se dirija a los establecimientos señalados en el precepto, entre ellos las farmacias ${ }^{59,60}$ aplicando también al Artículo 309 bis, Fracción IV. Que prohíbe la publicidad de cigarros en farmacias.

T) 6 de junio de 2006. Se modificó por vigésimo séptima vez la Ley General de Salud, al reformar el Artículo 277, ${ }^{61}$ Por razones de orden público e interés social, no se distribuirán cigarros en los sitios que tienen como objeto social la conservación de la salud como las farmacias.

U) 27 de diciembre de 2006. Se publicó en el DOF otra modificación a la LIEPS ${ }^{62}$, gravando los cigarros, puros y otros tabacos labrados con una tasa de $160 \%$ con gradualidad anual, $140 \%$ en 2007 y $150 \%$ en 2008. Los puros y otros tabacos labrados hechos enteramente a mano con $30.4 \%$, gradual de $26.6 \%$ en 2007 y $28.5 \%$ en 2008 .

La motivación fue desincentivar el consumo del tabaco y fortalecer las finanzas estatales para atender asuntos de salud.

V) Mayo de 2007. La SCJN emitió la Tesis Jurisprudencial $^{63}$ señalando que el vicio de inconstitucionalidad del $3^{\text {er }}$ Párrafo del Artículo 277 de la LGS vigente a partir del 20 de enero de 2004, declarado por la Primera y la Segunda Salas de la Suprema Corte de Justicia de la Nación al resolver los amparos en revisión de donde derivaron las jurisprudencias $1^{1}$. $. / J 40 / 2005$ y $2^{\text {a }}$./J. 31/2005, respectivamente, en relación con la prohibición de vender y distribuir cigarrillos en farmacias, no fue superado en la reforma a dicho párrafo publicada en el DOF el 6 de junio de 2006, con la inclusión en su texto de la leyenda "Por razones de orden público e interés social", toda vez que no están justificados esos motivos, cuyo argumento esencial para considerar que esa prohibición debe prevalecer por las razones indicadas, lo hace desprender de que las farmacias no vendan productos que pongan en riesgo la salud de los individuos, como lo son los cigarrillos; sin embargo, eso no explica por qué sí pueden venderse en cualquier otro establecimiento mercantil (con excepción de los contenidos en el propio tercer párrafo), lo cual es contrario a la garantía de libertad de comercio contenida en el Artículo 5o de la Constitución Política de los Estados Unidos Mexicanos, máxime que se da un trato diferente a quienes se dedican exclusivamente a la actividad de farmacia, y se omite mencionar a los que se dedican a la actividad de farmacia y minisúper, o a los grandes establecimientos comerciales en los que se incluye el servicio de farmacia y los demás establecimientos mercantiles con giros distintos a los anteriores.

\section{Ley General para el Control del Tabaco (LGCT)}

El proceso legislativo para la formulación de la propuesta de la LGCT (anexo 1) se sustentó en la elaboración de una política basada en evidencias ante los resultados poco satisfactorios con las políticas formuladas en los últimos 25 años. Se elaboró un modelo de proyecto y luego fueron dándose aproximaciones con la participación interactiva de múltiples actores a niveles personal e institucional en las diferentes disciplinas y sectores.

La experiencia obtenida por los procesos legislativos para hacer enmiendas en materia de tabaco que aún están vigentes en el proceso legislativo en ambas cámaras y la lectura crítica de la literatura disponible jugaron un papel clave para establecer las estrategias que se utilizaron ante las restricciones que sabíamos se iban a presentar a lo largo de la formulación y aprobación de la Ley.

La iniciativa fue presentada el 31 de agosto de 2007 en la Comisión Permanente de la LX Legislatura, segundo periodo de receso del primer año legislativo. Una segunda iniciativa que expide la Ley General para la Protección de la Salud de los Fumadores y No Fumadores fue presentada el 20 de septiembre de 2007 en la Cámara de Diputados en el primer periodo ordinario del segundo año legislativo.

Ambas iniciativas fueron turnadas a la Comisión de Salud. A pesar de la enorme controversia causada, particularmente en sectores afectados comercialmente, y posterior a diversas reuniones con todos los actores, se elaboró el Proyecto de Dictamen a la LGCT, aprobándose por Unanimidad en la Comisión el 21 de noviembre de 2007. La presión de los intereses creados aumentó de manera significativa en los siguientes días, llevando a cabo más reuniones de consenso, teniendo las últimas incluso durante la misma sesión del 6 de diciembre de 2007, posponiéndose por varias horas su votación en el pleno, donde se presentó un estudio que establecía que la LGCT no tenía vicios de inconstitucionalidad. El 
Dictamen que creaba la LGCT fue aprobado por amplia mayoría.

La minuta fue enviada para sus efectos constitucionales al Senado y turnada a las Comisiones Unidas de Salud; Medio Ambiente, Recursos Naturales y Pesca; y de Estudios Legislativos. El denominado cabildeo fue también intenso multiplicándose las reuniones y presiones. El proyecto de Dictamen de la minuta fue aprobada por unanimidad el 14 de febrero de 2007.

El Consejo Mexicano Contra el Tabaco y Parametría ${ }^{64}$ hicieron pública una encuesta de representatividad nacional con $95 \%$ de confianza donde el $81 \%$ de los encuestados estaba de acuerdo con una iniciativa que prohíba fumar en espacios públicos cerrados. Los espacios públicos en los que la mayoría está de acuerdo en que se prohíba fumar son las instituciones de salud (91\%), el transporte público (85\%), los centros comerciales y lugares de trabajo (83\%). Dicha encuesta más la influencia de los medios de comunicación que informaban de la aceptación por parte de la sociedad superior a ocho de cada diez, fueron factores determinantes para crear un ambiente favorable en los días previos a su análisis y votación en el pleno del Senado.

El pleno del Senado de la República aprobó la Minuta por amplia mayoría en los Términos que fue enviada de la Cámara de Diputados el martes 26 de febrero de 2008, turnándose al Ejecutivo Federal para los efectos constitucionales. ${ }^{65}$

Al 21 de abril de 2008 la Ley General para el Control del Tabaco no ha sido promulgada en el DOF. La Constitución señala en su Artículo 72, Fracción B: “Se reputará por aprobado por el Poder Ejecutivo, todo proyecto no devuelto con observaciones a la Cámara de su Origen, dentro de diez días útiles...". Dado que ha transcurrido cuatro veces dicho periodo, se está en espera sólo de la promulgación en los siguientes términos de la LGCT en el DOF a fin que tengan los efectos legales.

Podemos concluir, que la Ley General para el Control del Tabaco, es un precedente histórico donde se ha privilegiado el derecho a la salud de los ciudadanos. Sin embargo, aún queda un camino por recorrer en la prevención y control del tabaquismo en México y la región, entre los puntos sustantivos que se incluyen están los siguientes:

Futuras leyes gubernamentales deberán promover la reducción del nivel de cotinina en productos de tabaco, que coadyuvarán a reducir la dependencia y hacer más fácil la cesación.

Los programas de cesación de tabaquismo deberán tener una cobertura universal y estar cubiertos en programas nacionales de salud.

Campañas educativas en el ámbito escolar y de difusión mediática deberán implementarse para crear programas de prevención de adicciones desde temprana edad.

Las restricciones futuras, deberán considerar a los padres, para que en vehículos y hogares, particularmente donde habitan niños, se promueva la nula exposición.

El incremento de impuestos, continúa siendo una alternativa para disminuir el tabaquismo, particularmente en grupos vulnerables.

\section{Referencias}

I. Saenz-de-Miera-Juárez B, Jimenez-Ruiz JA, Reynales-Shiguematzu LM. La economía del tabaco en México. México: Instituto Nacional de Salud Pública, 2007:1-76.

2. Córdova-Villalobos JÁ. Programa Sectorial de Salud 2007-2012. Por un México sano: construyendo alianzas para una mejor salud. DOF I7/Ene/2008. Diario Oficial de la Federación 2008; I (I):I-24.

3. Zinser JW. El papel de las organizaciones no gubernamentales en la lucha antitabáquica. El Consejo Mexicano contra el Tabaquismo. Salud Publica Mex 2007;49(supl 2):SI33-SI36.

4. Villalobos A, Rojas R. Consumo de tabaco en México. Resultados de las Encuestas Nacionales de Salud 2000 y 2006. Salud Publica Mex 2007;49(supl 2):SI47-SI54.

5. Valdés-Salgado R, Reynales-Shigematsu LM, Lazcano-Ponce E, Hernández-Ávila M. Antes y después del Convenio Marco en México: una comparación desde la Encuesta sobre Tabaquismo en Jóvenes 2003 y 2006. Salud Publica Mex 2007;49(supl 2):SI55-SI69.

6. Thrasher JF, Hammond D, Fong GT, Arillo-Santillan E. Smokers' reactions to cigarette package warnings with graphic imagery and with only text: a comparison between Mexico and Canada. Salud Publica Mex 2007;49(supl 2):S233-S240.

7. Sánchez-Zamorano LM, Ángeles-Llerenas A, Anaya-Ocampo R, LazcanoPonce E. Prevalencia del uso de drogas ilegales en función del consumo de tabaco en una muestra de estudiantes en México. Salud Publica Mex 2007;49(supl 2):SI82-SI93.

8. Samet JM, Wipfli H. The Bloomberg Global Initiative to Reduce Tobacco Use. Salud Publica Mex 2007;49(supl 2):S3I2-S3I4.

9. Reynales-Shigematsu LM, Vázquez-Grameix JH, Lazcano-Ponce E. Encuesta Mundial de Tabaquismo en Estudiantes de la Salud, México 2006. Salud Publica Mex 2007;49(supl 2):SI94-S204.

10. Regalado-Pineda J, Lara-Rivas G, Osio-Echánove J, Ramírez-Venegas A. Tratamiento actual del tabaquismo. Salud Publica Mex 2007;49(supl 2): S270-S279.

I I. Ponciano-Rodríguez G, Morales-Ruiz A. La escritura emocional como una herramienta para el tratamiento psicológico del tabaquismo. Salud Publica Mex 2007;49(supl 2):S280-S289.

I2. Ponciano-Rodríguez G, Morales-Ruiz A. Evaluación del Programa de Tratamiento para la Cesación del Tabaquismo en la clínica de la Facultad de Medicina de la UNAM. Salud Publica Mex 2007;49(supl 2):S247-S256.

13. Peruga A. Protección contra la exposición al humo de tabaco ajeno: recomendaciones de la OMS. Salud Publica Mex 2007;49(supl 2): S3I5-S3I7.

14. Madrazo-Lajous A, Zambrano-Porras JL. Análisis jurídico del convenio entre la SSA y la industria tabacalera. Estudio de caso. Salud Publica Mex 2007;49(supl 2):S290-S30I.

I5. Lazcano-Ponce E, Sánchez-Zamorano LM, Benowitz N, BarbosaSánchez L, Hernández-Ávila M. Elevada concentración de metabolitos de cotinina en hijos de padres fumadores. Salud Publica Mex 2007;49(supl 2): S213-S223.

16. Lara-Rivas G, Ramírez-Venegas A, Sansores-Martínez RH, Marlene 
Espinosa A, Regalado-Pineda J. Indicadores de síntomas de abstinencia en un grupo de fumadores mexicanos. Salud Publica Mex 2007;49(supl 2): S257-S262.

17. Hernández-Ávila M, Rodríguez-Ajenjo C], García-Handal KM, IbáñezHernández NA, Martínez-Ruiz MJ. Perspectivas para el control del tabaquismo en México: reflexiones sobre las políticas actuales y acciones futuras. Salud Publica Mex 2007;49(supl 2):S302-S3II.

18. Hernández-Ávila JE, Tirado-Ramírez E, Santos-Luna R, ReynalesShigematsu LM. Use of Geographical Information Systems for billboards and points-of-sale surveillance in two Mexico cities. Salud Publica Mex 2007;49(supl 2):S24I-S246.

19. De Miera-Juarez BS, Jimenez-Ruiz JA, Reynales-Shigematsu LM, Lazcano-Ponce E, Hernandez-Avila M. Household tobacco consumption in Mexico, 1994-2005. Salud Publica Mex 2007;49(supl 2):S263-S269.

20. Córdova-Villalobos JÁ. Hacia espacios $100 \%$ libres de humo de tabaco. Salud Publica Mex 2007;49(supl 2):SI3I-SI32

2I. Barrientos-Gutiérrez T, Valdés-Salgado R, Reynales-Shigematsu LM, Navas-Acien A, Lazcano-Ponce E. Exposición involuntaria al humo de tabaco en lugares públicos de la Ciudad de México. Salud Publica Mex 2007;49(supl 2):S205-S2I2.

22. Barrientos-Gutiérrez T, Reynales-Shigematsu LM, Ávila-Tang E, Wipfli H, Lazcano-Ponce E. Exposición al humo de tabaco en hogares de la Ciudad de México: análisis de nicotina ambiental y en cabello de niños y mujeres. Salud Publica Mex 2007;49(supl 2):S224-S232.

23. Arillo-Santillán E, Thrasher J, Rodríguez-Bolaños R, Chávez-Ayala R, Ruiz-Velasco S, Lazcano-Ponce E. Susceptibilidad al consumo de tabaco en estudiantes no fumadores de 10 ciudades mexicanas. Salud Publica Mex 2007;49(supl 2):SI70-SI8I

24. Aguilar-Navarro SG, Reyes-Guerrero J, Borgues G. Cognitive impairment and alcohol and cigarette consumption in Mexican adults older than 65 years. Salud Publica Mex 2007;49(supl 4):S467-S474. 25. Valdés-Salgado R, Thrasher J, Sánchez-Zamorano LM, Lazcano-Ponce E, Reynales-Shigematsu LM, Meneses-González F, et al. Los retos del Convenio Marco para el Control del Tabaco en México: un diagnóstico a partir de la Encuesta sobre Tabaquismo en Jóvenes. Salud Publica Mex 2006;48(supl I):S5-SI6

26. Valdes Salgado R, Hernandez-Avila M. Mexico without tobacco. Salud Publica Mex 2006;48(supl I):SI-S3.

27. Urquieta JE, Hernández-Ávila M, Hernández B. El consumo de tabaco y alcohol en jóvenes de zonas urbanas marginadas de México. Un análisis de decisiones relacionadas. Salud Publica Mex 2006;48(supl I):S30-S40.

28. Thrasher JF, Chaloupka F, Hammond D, Fong G, Borland R, Hastings

$\mathrm{G}$, et al. Evaluación de las políticas contra el tabaquismo en países latinoamericanos en la era del Convenio Marco para el Control del Tabaco. Salud Publica Mex 2006;48(supl I):SI55-SI66.

29. Thrasher JF, Allen B, Reynales-Shigematsu LM, Anaya R, Lazcano-Ponce E, Hernández-Ávila M. Análisis del impacto en fumadores mexicanos de los avisos gráficos en las cajetillas de cigarros. Salud Publica Mex 2006;48(supl I):S65-S74.

30. Sánchez-Zamorano LM, Hernández-Ávila M, Lazcano-Ponce E. El consumo inmoderado de alcohol como factor predictor de la persistencia del consumo de tabaco en jóvenes. Salud Publica Mex 2006;48(supl I): S4I-S47.

31. Ross $\mathrm{H}$, Chaloupka FJ. Economic policies for tobacco control in developing countries. Salud Publica Mex 2006;48(supl I):SI I3-SI20. 32. Rodríguez T, Gallus S, Chatenoud L, Zuccaro P, Colombo P, Apolone G, et al. Efecto de la nueva regulación antitabaco en Italia. Salud Publica Mex 2006;48(supl I):SI37-SI39.

33. American-Cancer-Society, International-Union-Against-Cancer, Campaign-for-Tobacco-Free-Kids. ENACTING Strong SMOKE-FREE Laws: The Advocate's Guide to Legislative Strategies. Guide \# 3. USA: American Cancer Society, International Union Against Cancer, Campaign for Tobacco-Free Kids, 2006.

34. American-Cancer-Society, International-Union-Against-Cancer,
Campaign-for-Tobacco-Free-Kids. ENFORCING Strong SMOKE-FREE Laws: The Advocate's Guide to Enforcement Strategies. USA.: American Cancer Society, International Union Against Cancer, Campaign for Tobacco-Free Kids, 2006.

35. Conferencia de las partes en el Convenio Marco de la OMS para el Control del tabaco. Elaboración de directrices para la aplicación del Convenio, FCTC/COPI, 2007.

36. Ramírez-Barba EJ, Arenas-Guzmán M, Muñoz-Serrano JA, SalazarMadera MA. Dictamen de la Segunda Comisión, por el que se exhorta al Titular del Ejecutivo Federal, para que informe del estado que guarda el reporte a que hace referencia el Convenio Marco de la Organización Mundial de la Salud para el Control del Tabaco. Aprobado en Votación económica. Comisión Permanente, Segundo Receso. Gaceta del Senado. 13/06/2007 ed. México, DF: Cámara de Senadores LIX Legislatura, 2007. 37. Ramírez-Barba EJ, Saro-Boardman E, Vega-Ortiz O, Mayans-Canabal F, Galván-Rivas A, Abad-de-Jesús J, et al. Iniciativa por la que se crea la Ley General para el Control del Tabaco, y se derogan diversos artículos de la Ley General de Salud. Gaceta Del Senado. 3I/08/2007 ed. México, DF: Cámara de Diputados LX Legislatura, 2007.

38. Ruiz-Cortínes A. Código Sanitario de los Estados Unidos Mexicanos de 1955: Última actualización I de marzo de 1955. Diario Oficial. México, DF: Secretaría de Gobernación, 1955:I-25.

39. CDIA. Adolfo Ruiz Cortínes- RE-ISS-09-06-II. Adolfo Ruiz Cortines. México: Centro de Documentación, Información y Análisis de la H. Cámara de Diputados, 2006: 117.

40. CDIA. Adolfo López Mateos- RE-ISS-09-06-I2. Adolfo Ruiz Cortínes. México: Centro de Documentación, Información y Análisis de la $\mathrm{H}$. Cámara de Diputados, 2006:24,88, I45,278.

4I. Echeverría-Álvarez L. Código Sanitario de los Estados Unidos Mexicanos de 1973: Octavo. Última actualización II de marzo de 1973. Diario Oficial. México, DF: Secretaría de Gobernación; 1973I-5I. 42. CDIA. Luis Echeverría Álvarez- RE-ISS-09-06-14. Informes Presidenciales. México: Centro de Documentación, Información y Análisis de la H. Cámara de Diputados, 2006:36,48,196,289,403.

43. CDIA. José López Portillo- RE-ISS-09-06-15. Informes Presidenciales. México: Centro de Documentación, Información y Análisis de la H. Cámara de Diputados, 2006:36,48,196,289,403.

44. Congreso-de-la-Unión-LIX-Legislatura. Ley General de Salud (0) Diario Oficial de la Federación. 1984/02/07 ed. México, DF: Congreso General, 1984.

45. CDIA. Miguel de la Madrid Hurtado- RE-ISS-09-06-16. Informes Presidenciales. México: Centro de Documentación, Información y Análisis de la H. Cámara de Diputados; 2006:189.

46. Congreso-de-la-Unión-LIX-Legislatura. DECRETO por el que se reforma y adiciona la Ley General de Salud (I). Diario Oficial de la Federación. 27/05/I987 ed. México, DF: Congreso General, 1987. 47. Congreso-de-la-Unión-LIX-Legislatura. DECRETO que reforma, adiciona y deroga diversas disposiciones de la Ley General de Salud (3). Diario Oficial de la Federación. I4/06/198I ed. México, DF: Congreso General, 1991.

48. CDIA. Carlos Salinas de Gortari- RE-ISS-09-06-17. Informes Presidenciales. México: Centro de Documentación, Información y Análisis de la H. Cámara de Diputados, 2006;189.

49. Congreso-de-la-Unión-LIX-Legislatura. DECRETO por el que se modifica la fracción II del artículo I 88 de la Ley General de Salud (6). Diario Oficial de la Federación. 31/5/2000 ed. México, DF: Congreso General, 2000.

50. Zedillo-Ponce-de-León E. Reglamento sobre Consumo del Tabaco. Diario Oficial de la Federación. 27/07/2000 ed. México, DF: Congreso General, 2000.

51. Congreso-de-la-Unión. Ley del Impuesto Especial sobre Producción y Servicios. Disponible en: http://diariooficial.segob.gob.mx/nota_detalle. php? codigo $=737409 \& \operatorname{cod}=737409$. Diario Oficial de la Federación. 
I/0I/2002 ed. México, DF: Congreso General, 2002.

52. Congreso-de-la-Unión-LIX-Legislatura. Decreto por el que se reforman, adicionan y derogan diversas disposiciones de la Ley al Valor Agregado, de la Ley del Impuesto sobre la Renta, de la Ley del Impuesto Especial sobre Producción y Servicios, de la Ley sobre Tenencia o Uso de Vehículos, de la Ley Federal del Impuesto sobre Automóviles nuevos y de la Ley Federal de Derechos. Diario Oficial de la Federación. 3I//2/2003 ed. México, DF: Congreso General, 2003.

53. Congreso-de-la-Unión-LIX-Legislatura. Decreto por el que se reforman y adicionan diversas disposiciones de la Ley General de Salud en relación a la publicidad del tabaco (14). Diario Oficial de la Federación. 19/0I/2004 ed. México, DF: Congreso General, 2004.

54. Secretaría-de-Relaciones-Exteriores. Decreto por el que se aprueba el Convenio Marco de la OMS para el Control del Tabaco, adoptado en Ginebra, Suiza, el veintiuno de mayo de dos mil tres. Diario Oficial de la Federación. 12/05/2004 ed. México, DF: Cámara de Senadores, 2004. 55. Consejo-de-Salubridad-General. Acuerdo por el que se emite recomendación a fin de proteger la salud de los no fumadores por la exposición involuntaria al humo del tabaco. Diario Oficial de la Federación. 28/05/2004 ed. México, DF: Consejo de Salubridad General, 2004.

56. SHCP. Decreto por el que se exime del pago de los impuestos especiales sobre producción y servicios y el valor agregado a los contribuyentes que se indican. Diario Oficial de la Federación. 30/07/2004 ed. México, DF: Secretaría de Hacienda y Crédito Público, 2004. 57. Secretaría-de-Relaciones-Exteriores. Decreto Promulgatorio del Convenio Marco de la OMS para el Control del Tabaco, adoptado en Ginebra, Suiza, el veintiuno de mayo de dos mil tres. Diario Oficial de la Federación. 25/02/2005 ed. México, DF: Cámara de Senadores, 2005. 58. SCJN. Tesis 2a/J. 3I/2005 Cigarros. La prohibición de su venta o distribución en farmacias o boticas, a que se refiere el artículo 277, tercer párrafo de la Ley General de Salud, en vigor a partir del 20 de enero de 2004, viola la garantía de libertad de comercio. Semanario Judicial de la Federación y su Gaceta Novena época. 2005 25/02/2005;XXI(Marzo):228. 59. SCJN. Tesis Ia/J. 40/2005 Ley General de Salud, el artículo 277, párrafo tercero, en vigor a partir del 20 de enero de 2004, que prohíbe la venta de cigarros en farmacias, viola la garantía de libertad de comercio.
Semanario Judicial de la Federación y su Gaceta Novena época. 2005 30/03/2005;XXI(Abril):378.

60. SCJN. Tesis Ia/J. XXIX/2005 Ley General de Salud, el artículo 309 bis, fracción IV, en vigor a partir del 20 de enero de 2004, que prohíbe la publicidad de cigarros en farmacias, viola la garantía de libertad de comercio. Semanario Judicial de la Federación y su Gaceta Novena época. 2005 30/03/2005;XXI(Abril):726.

61. Congreso-de-la-Unión-LIX-Legislatura. Decreto por el que se reforma el tercer párrafo del artículo 277 de la Ley General de Salud (27). Diario Oficial de la Federación. 06/06/2006 ed. México, DF: Congreso General, 2006.

62. Congreso-de-la-Unión-LIX-Legislatura. DECRETO por el que se reforma la Ley del Impuesto Especial sobre Producción y Servicios. México, DF: Congreso General, 2006 [updated 2006; cited]; 27//2/2006:[80]. Disponible en: http://diariooficial.segob.gob.mx/nota_ detalle.php? codigo $=4941637$.

63. SCJN. Tesis Ia. ClII/2007 Cigarros. La prohibición de su venta en farmacias, en los términos del artículo 277 , tercer párrafo de la Ley General de Salud, reformado mediante decreto publicado en el Diario Oficial de la Federación el 6 de junio de 2006, vigente a partir del día siguiente, viola la garantía de libertad de comercio. Semanario Judicial de la Federación y su Gaceta Novena época. 2007 0I/03/2005;XXV(Mayo):789. 64. Tabaquismo. Reporte Ejecutivo. México: Parametría. Investigación Estratégica. Análisis de Opinión y Mercado; 2008. Report No.: 916/02/2008 Contract No.: Document Number. 65. Zavaleta-Salgado R, Creel-Miranda S, Maciel-Ortíz MM, CuéMonteagudo G. Decreto: Se expide la Ley General para el Control del Tabaco; y deroga y reforma diversas disposiciones de la Ley General de Salud. Exp. 2223. Oficio No. DGPL-2P2A.-4I28. 26 de Febrero de 2008. México: Congreso General de los Estados Unidos Mexicanos, LX Legislatura; 2008. 